\title{
INFANTILE HYPERTROPHIC PYLORIC STENOSIS RECURRING AFTER RAMMSTEDT'S OPERATION
}

BY

\author{
N. K. MACRAE-GIBSON and B. L. COLES \\ From the Victoria Hospital for Children and the Elizabeth Garrett Anderson Hospital, London
}

(RECEIVED FOR PUBLICATION NOVEMBER 20, 1952)

Since the introduction of Rammstedt's operation for the treatment of infantile pyloric stenosis the mortality rate has steadily fallen; the principal cause of death is now gastro-enteritis or some other intercurrent infection. The incidence of true recurrence of symptoms also appears to be low. Tallerman (1951), Ladd, Ware and Pickett (1946), Paterson (1941), Dobbs (1941), Donovan (1937) and Bolling (1925) all reported large series with no mention of relapse. The persistence of some vomiting during the first few days after operation is common and is usually attributed to long-standing gastric distension with gastritis. This can be minimized by reducing the feeds and in severe cases by stopping all oral feeding and substituting parenteral fluids (Wood and Smellie, 1951; Grimes, Bell and Olney, 1950; Szilagyi and McGraw, 1943; Jewesbury and Page, 1937; Parsons and Barling, 1923). Faber and Davis (1940) have shown that gastric peristalsis is completely inhibited for several hours after operation and depressed for $\mathbf{2 4}$ hours or more. They relate this depression to post-operative distension and vomiting and claim to have greatly reduced the incidence of vomiting by withholding all oral feeds for 24 hours after operation and giving only parenteral fluids.

In this paper we present two cases in which an apparently adequate Rammstedt's operation was followed by a complete recurrence of all symptoms and signs of pyloric stenosis which failed to respond to 'eumydrin' and for which each patient required a second operation. At operation in each case a typical pyloric tumour was again found. After the second operation vomiting again persisted, and pyloric obstruction by a typical pyloric tumour was demonstrated both clinically and radiologically. Both infants eventually recovered with further medical treatment.

\section{Case Reports}

Case 1. C.E. was a normal full term boy (birth weight $7 \mathrm{lb} .9 \mathrm{oz}$.). He was the third child: the others were both healthy and there was no family history of pyloric stenosis. He was fully breast fed, and began to vomit when 2 weeks old. He failed to respond to out-patient treatment with 'eumydrin' and was admitted to hospital aged 19 days. On examination, projectile vomiting, visible peristalsis and a palpable pyloric tumour were present. When aged 22 days a Rammstedt's operation was performed under general anaesthesia and a large pyloric tumour divided. Small vomits persisted after operation but were controlled with $0 \cdot 6^{\circ}$ o alcoholic 'eumydrin', minims 1, before all eight feeds. He was discharged 35 days after operation. Vomiting began again immediately and he was admitted again after a further week. A barium meal showed spasm of the pylorus, only half the meal having left the stomach after one hour. Three days later, aged 67 days and $\mathbf{4 5}$ days after the first operation, a second operation was performed under general anaesthesia. Adhesions were present between the intestines, liver and peritoneum, but these were not $\bar{c}$ causing obstruction, and a typical pyloric tumour was? again present. The previous incision was replaced by a fibrous scar. The tumour was redivided, and the duodenum was opened at one point and satisfactorily closed. Slight post-operative vomiting occurred but the infant's general condition remained good and he gained weight. The vomiting became severe and projectile during the second week after operation and did not respond to gastric wash-outs and glyceryl trinitrite, grain $\frac{1}{100}$, daily. Two weeks after the second operation, aged 82 days, he was transferred to the Victoria Hospital for Children. His weight was then $7 \mathrm{lb}$. $9 \frac{3}{\mathrm{oz}}$. On examination, he was dehydrated with visible peristalsis and a palpable pyloric tumour. A further barium meal (two months after the first operation, and two weeks after the second operation) showed typical pyloric stenosis (Fig. 1). After rehydration with subcutaneous salines, 'eumydrin'. minims 2, eight times daily, was started and the vomiting responded well. The dose was gradually reduced and discontinued after five weeks. He was discharged seven weeks after admission, weighing $10 \mathrm{lb}$. $11 \frac{1}{2} \mathrm{oz}$., free from symptoms and on full feeds.

Case 2. S.W., a boy of birth weight $6 \mathrm{lb}$. $6 \mathrm{oz}$., was born three weeks prematurely. The mother was $R h$ negative, the child $R h$ positive but there was no evidence of erythroblastosis. He was the second child, the other was well, and there was no family history of pyloric stenosis. He was breast fed for five weeks when he began vomiting, and breast feeding was discontinued. He was 
tried on three different dried milks but the vomiting increased. All feeds had been vomited for 10 days before

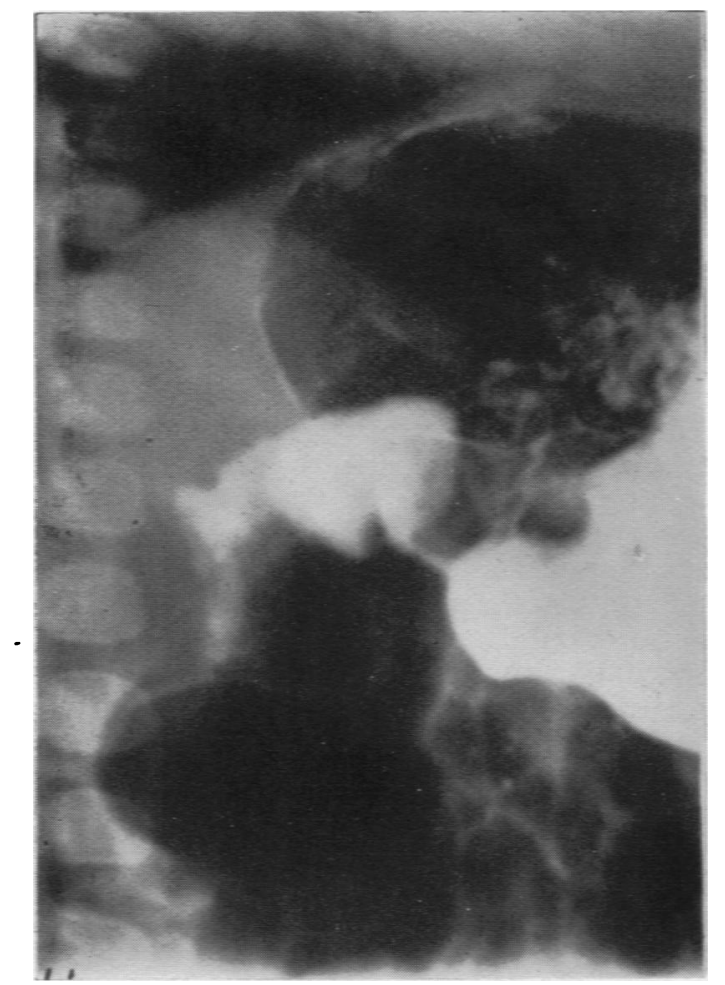

FKG. 1.-Two months after the first operation and two weeks after the second operation showing after a barium meal typical pyloric stenosis.

admission and the vomiting was projectile in character. He had been constipated for several days before admission. On examination, he was slightly dehydrated with visible peristalsis and a palpable tumour. 'Eumydrin', minims 5 and 6 before alternate feeds (five feeds daily), was tried for five days without success. The next day (aged 9 weeks) Rammstedt's operation was performed under local anaesthesia, and a typical tumour was found. Vomiting continued after operation with gastric residues of 3 to $6 \mathrm{oz}$. daily. Four days after operation 'eumydrin' was restarted and increased to 4 minims before feeds without effect. Twelve days after the first operation a second Rammstedt's operation was performed under general anaesthesia and a pyloric tumour was again found. This was redivided. The infant's postoperative condition was poor with haematemesis and melaena requiring intravenous fluids and blood transfusion. He also developed some sepsis in the wound which responded to penicillin and streptomycin. Oral feeding was began four days after operation. On the tenth day after the second operation vomiting again began with gastric residues of 2 to $4 \frac{1}{2} \mathrm{oz}$. daily. Radiographs showed persistence of pyloric obstruction on screening. 'Eumydrin' was tried again and the dosage increased to 8 minims before all five feeds. The vomiting gradually decreased, the gastric residues fell to $1 \frac{1}{2}-2 \mathrm{oz}$. daily, and he slowly gained weight. Fourteen and a half weeks from the second operation a barium meal still showed total obstruction at the pylorus up to 10 minutes after the meal (Fig. 2). Unfortunately no further films were taken. The child was then discharged (aged 5 months) on 'eumydrin', minims 8 before meals, with only occasional vomiting, and weighing $11 \mathrm{lb}$. $2 \frac{1}{2} \mathrm{oz}$. His subsequent progress was uneventful apart from acute otitis media at the age of 8 months. When aged 11 months a further barium meal showed normal emptying of the stomach. The 'eumydrin' was stopped over the next two weeks with no return of vomiting and he has remained well.

\section{Discussion}

Aird (1949) believes that continued vomiting after Rammstedt's operation suggests incomplete division of the tumour and most authorities are in agreement. References to incomplete division found at necropsy or at second operations are made by Ward-McQuaid and Porritt (1950) who reported one case where incomplete section was found at necropsy. They considered re-operation in a second case but the child responded to medical treatment. Grimes et al. (1950) cite one case of recurrence, the second operation being performed through a different area. Frazier and Warfield (1949) consider that inadequate division was the cause of continued vomiting in their case, which was re-operated on six weeks after the

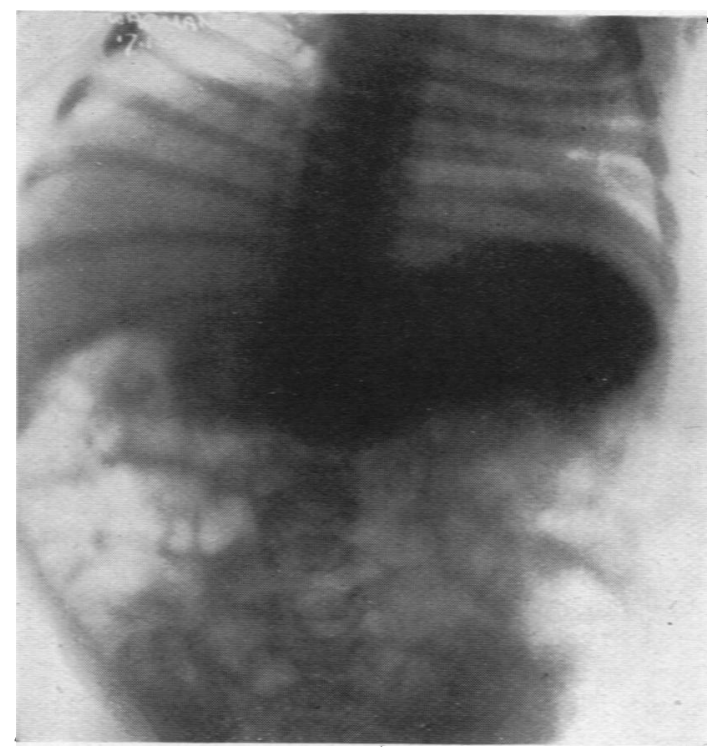

Fkg. 2--Film taken 10 minutes after a barium meal showing total obstruction $14 \frac{1}{2}$ weeks after second operation. 
first operation and again found to have a typical tumour. Schaefer and Erbes (1948) mention five cases requiring re-operation. All recurrences were thought to be due to inadequate surgery. Jacoby (1944) reports a case where vomiting persisted after operation, but no further surgery was undertaken because of the infant's poor general condition. The child subsequently died but there is no mention of the state of the pylorus at necropsy. Szilagyi and McGraw (1943) in an extensive paper suggest that failures after operation were due to incomplete section of the muscular fibres although the gross anatomy appeared adequate at the time of operation. They also suggest that some nervous pathway as yet unidentified may play a part in the causation of pyloric stenosis, and that failure to divide these may be the cause of some recurrences. They give the incidence of recurrence as approximately $2 \%$ after correction has been made for cases of mistaken diagnosis, but from the cases reviewed in this paper the incidence appears to be nearer $0 \cdot 3 \%$. They report one case of their own which responded to a second operation. Jewesbury and Page (1937) had two recurrences in their series. One had a further operation but died, the other infant died without a second operation.- Thompson and Gaisford (1935) also thought recurrences due to inadequate surgery but reported no cases of their own. Lanman and Mahoney (1933) had two cases requiring further surgery. In both cases at re-operation the tumour was found to have been incompletely divided. Gaisford (1931) and Still (1923) each reported one case of relapse after operation. In Gaisford's case, re-operation took place 26 days after the first operation, and a second tumour was found proximal to the original one. He considered that fibres at the gastric end of the first tumour were not completely sectioned, and attributed the relapse to this.

Another possible cause of recurrence of symptoms after operation is the formation of adhesions resulting in obstruction. Donovan (1946) reported a case in which the symptoms were relieved after division of adhesions. Rinvik (1940) reported two cases of relapse. One recovered after a second Rammstedt's operation but the second patient continued to vomit, and at a third operation adhesions were thought to be the cause. Miller (1946) treated a case of relapse by gastro-enterostomy but gave no definite cause for the continuation of symptoms. A duodenal membrane or some similar abnormality was suspected. The only case in which a true recurrence of the tumour was suggested was in that reported by Rosenblum (1950). A typical simall tumour was found at the first operation and the infant progressed satisfactorily for two weeks. He then developed eczema and gastro-enteritis and started to vomit. The vomiting continued and 69 days after operation a barium meal showed signs of pyloric stenosis. A further operation was performed three days later and the site of the previous operation could not be identified. Although Rosenblum agrees that relapses are usually due to inadequate surgery, he believed this case to be one of true recurrence because of the length of time between the two operations, the symptoms having completely abated for a time and the child having gained $72 \mathrm{oz}$. Severe vomiting ceased after the second operation but there were still occasional attacks of vomiting and eczema which were thought to be due to food allergy. Frazier and Warfield also mentioned the connexion of allergy with pyloric stenosis, as a child reported by them only ceased vomiting completely after the second operation when a special diet and sedatives were given. There was no suggestion of allergy and no family history of it in either of our cases.

In both our cases, the second operation was performed with particular care and the macroscopic appearances were entirely satisfactory. We feel it unlikely that inadequate section could have been responsible for the continued symptoms after the second operation. Both tumours had recurred at the original site in contrast to Gaisford's case where the second tumour was proximal to the first. This excludes the possibility of incomplete division at the gastric end of the tumour which appears to be a common site in which a few fibres may escape section. In Gaisford's case 12 days elapsed after operation before the recurrence of symptoms. Other authors who consider their relapses due to inadequate surgery report the onset of vomiting any time from immediately after operation to 12 days post-operatively. In case 1 the exact time of recurrence of vomiting was rather masked by 'eumydrin' after the first operation but was definite at one month. Vomiting began again one week after the second operation. Case 2 continued to vomit after the first operation and vomiting began again 10 days after the second. While these times of remission are short, we do not feel that they necessarily prove that regeneration was taking place from fibres which were not completely divided. Post-mortem material suggests that after a clinically successful operation the gap between the fibres closes in two to three weeks (Wollstein, 1922). The tumour is then softer than at first and disappears completely after one to two months. This contrasts with the persistence of the tumour into adult life after gastro-enterostomy (Donovan, 1946; Holt, 1917). In our cases, the gap was found to be closed at the second operation at 
45 days and 12 days respectively. The tumours, however, were hard and presented a typical appearance as at the first operation. Normally the cut ends of the muscle are separated by a thin layer of fibrous connective tissue as healing proceeds and there is no attempt at proliferation. As an explanation for two relapses in our cases, we postulate an abnormal tendency of the pyloric fibres to proliferate.

The $x$-ray appearances are not a great help in the differential diagnosis of relapse, as after an apparently successful Rammstedt's operation abnormal radiological appearances may persist for some months (Olnick and Weens, 1949; Andresen, 1940; Runström, 1939). There seems no radiological means of distinguishing between a true recurrence or a relapse due to inadequate surgery, though $x$-rays are of use in excluding such conditions as duodenal membrane if vomiting persists after operation. That the pylorus in some cases shows normal $x$-ray appearances shortly after operation is shown in Fig. 3. This infant had a Rammstedt's operation two months before the radiograph was taken.

Whatever the cause of recurrence after operation

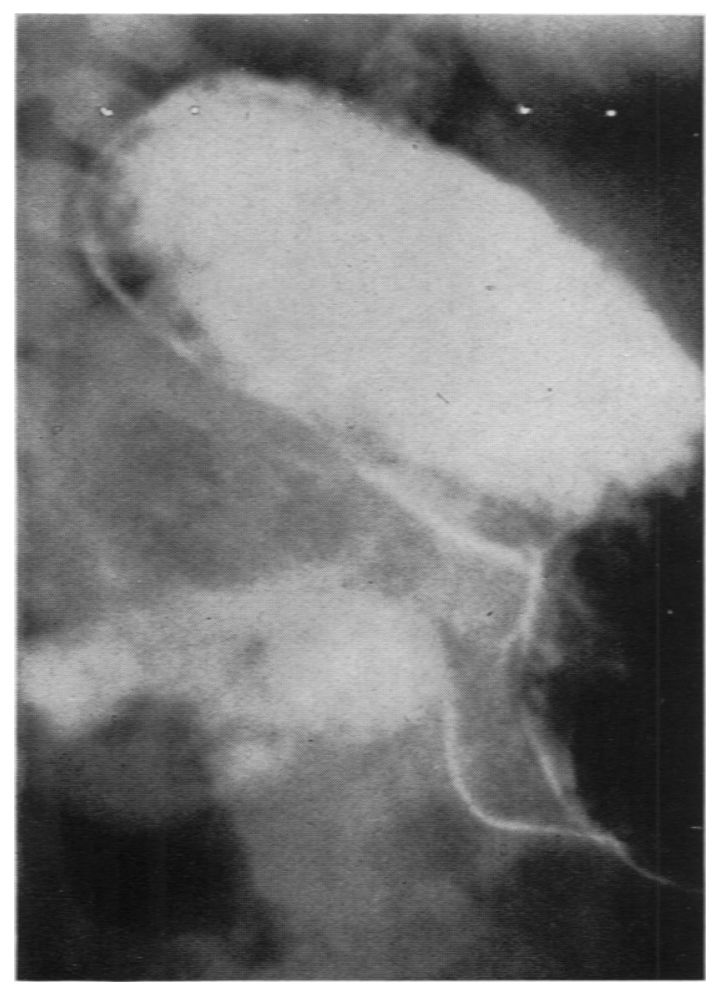

Frg. 3.-Radiograph taken two months after a successul Rammstedt's operation. The pyloric antrum, the pylorus and the first part of the duodenum are outlined with barium and air. the prognosis seems poor. If typical signs and symptoms recur after Rammstedt's operation the treatment of choice would appear to be a short trial of medical treatment with early operation if this does not produce a remission. A re-operation should not be deferred until the general condition has deteriorated. It is possible that a modification of the classical Rammstedt's operation might be more successful in cases of relapse. Grimes et al. (1950) reported less post-operation regurgitation in cases where an elliptical wedge of tissue was removed for histological section and this procedure might be worthy of trial in selected cases. The disadvantage of this operation is the increased risk of haemorrhage and formation of adhesions. If the second operation is unsuccessful prolonged medical treatment with an adequate dosage of 'eumydrin' and gastric lavage should be tried.

\section{Summary}

Two cases of pyloric stenosis recurging after Rammstedt's operation are reported. In each case a further recurrence occurred after a second operation. Both cases eventually responded to medical treatment.

The literature is reviewed and the likely causes of relapse are discussed.

It is suggested that true recurrences may be due to an abnormal tendency of the pyloric fibres to proliferate.

We wish to thank Mr. Gilchrist and Dr. Charles Pinckney for permission to publish case 1 , and Miss A. H. Baker and Dr. Ursula James for case 2.

\section{REFERENCES}

Aird Ian (1949). A Companion in Surgical Studies, p. 569. Edinburgh Andresen, K. (1940). Acta paediat., Uppsala, 27, 334.

Bolling, R. W. (1925). J. Amer. med. Ass., 85, 20

Dobbs, R. (1941). Proc. roy. Soc. Med., 35, 51 .

Donovan, E. J. (Ladd, W. E. and Strauss, A. A.) in discussion, Ladd, p. 560, Strauss, p. 561 (1937). J. Amer. med. Ass., 109, 558.

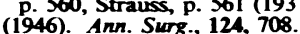

Faber, H. K and Davis, J. H. (1940). J. Amer. med. Ass., 114, 847.

Frazier, C. A. and Warfield, J. O. (1949). W. Va. med. J., 45, 235.

Gaisford, W. (1931). Archives of Disease in Childhood, 6, i11.

Grimes, O. F., Bell, H. G. and Olney, M. B. (1950). J. Pediat., 37, 522

Holt, L. E. (1917). J. Amer. med. Ass., 68, 1517.

Jacoby, N. M. (1944). Lancet, 2748.

Jewesbury, R. C. and Page, C. M. (1937). St. Thom. Hosp. Rep., 2nd lewer. 2,141 .

Ladd, W. E., Ware, P. F. and Pickett, L. K. (1946). J. Amer. med. Ass., 131, 647

Lanman, T. H. and Mahoney, P. J. (1933). Surg. Gynec. Obstet., 56, 205 .

Olnick, H. M. and Weens, H. S. (1949). J. Pediat., 34, 720.

Parsons, L. G. and Barling S. G. (1923). Lancet, 1, 59.

Paterson, D. (1941). Proc. roy. Soc. Med., 35, 49.

Rinvik, R. (1940). Acta paediat., Uppsala, 27, 295.

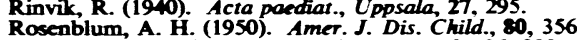

Runström, G. (1939). Acta paediat., Uppsala, 26. 383.

Schnefer, A. A. and Erbes, J. (1948). Surg. Gynec. Obstet., 86, 45

Still, G. F. (1923). Brit. med. J., 1, 579.

Szilagyi, D. E. and McGraw, A. B. (1943). Surgery, 13. 764.

Tallerman, K. H. (1951). Proc. roy. Soc. Med.. 44, 1055.

Talkman, K. H. (1951). Proc. roy. Soc. Med.. 44, loss. ${ }_{\text {. }} 1037$.

Ward-McQuaid, J. N. and Porritt, B. E. (1950). Lancet, 1, 201.

Wolkstein, M. (1922). Amer. J. Dis. Child., 23, 511.

Wood, E. C. and Smellie, J. M. (1951). Lancet ,2,3. 